ÁREA TEMÁTICA: MONITORAMENTO AMBIENTAL

\title{
ESTUDO DE CASO - MONITORAMENTO LIMINOLÓGICO E DA QUALIDADE DAS ÁGUAS DA PCH UNAI BAÍXO
}

ELIACIR JOSÉ DE SOUSA JUNIOR

eliacirjunior@hotmail.com

PATOS DE MINAS 


\section{RESUMO}

Esse artigo reporta os resultados obtidos campanha do Monitoramento Limnológico e da Qualidade das Águas da PCH Unaí Baixo, realizadas em outubro/2016 e janeiro/2017. O Brasil é movido basicamente por energia hidrelétrica, o que demanda a construção de reservatórios hídricos. Essa pratica, apesar de ser considerada uma energia limpa, causa impactos ao entorno. Nesse sentido, o acompanhamento ambiental nesses ambientes se faz necessário. Neste estudo de caso estão representados os resultados obtidos durante as campanhas. A qualidade da água na área de influência da PCH Unaí Baixo foi considerada boa. Assim, é importante ressaltar a necessidade da continuidade do monitoramento dos parâmetros físico-químicos e microbiológicos, com o objetivo de examinar alterações da qualidade da água e propor medidas quando necessário.

\section{INTRODUÇÃO}

A energia é uma das principais preocupações mundiais, já que a mesma é responsável pelo crescimento da produção e desenvolvimento da economia, sendo indispensável para a manutenção e desenvolvimento dos países. A rápida elevação da densidade demográfica em várias regiões do Brasil tem exigido um aumento constante na geração de energia elétrica, tendo suas necessidades suplantadas através da construção de barragens (CAVENAGHI et al., 2003), assim é necessário que haja a expansão na geração de energia, já que esta é essencial para o desenvolvimento socioeconômico (PEDREIRA, 2004).

No Brasil o suprimento energético é constituído em sua maioria através de hidrelétricas e a construção de reservatórios promovem alterações importantes no perfil do sistema rio e na formação de novos padrões, podendo gerar significativos impactos. Segundo Goulart \& Calistto (2003), impactos no ambiente aquático podem resultar na diminuição da diversidade de hábitats e na perda da biodiversidade.

Para que se tenha uma medida das alterações ocorridas nestes ambientes, torna-se necessário monitorar o comportamento dos novos ambientes formados, em conjugação com os efeitos das atividades antrópicas na região (uso da terra para atividades agrícolas, na sua maior parte).

Desta forma, os programas de monitoramento ambiental são primordiais para a identificação e avaliação dos impactos ambientais causados. É uma ferramenta essencial, que permite avaliar o estado de preservação e/ou grau de degradação dos ecossistemas e fornece 
subsídios para a implantação de estratégias de conservação de áreas naturais e planos de recuperação do ecossistema degradado (SOUZA, 2007).

O objetivo deste estudo é monitorar a qualidade da água em pontos localizados na área de influencia do reservatório da PCH Unaí Baixo.

\section{METODOLOGIA}

As atividades de monitoramento limnológico e da qualidade da água compreendem a coleta de amostras de água, a análise de parâmetros físico-químicos e microbiológicos.

As coletas e análises de amostras para obtenção dos resultados dos parâmetros físico-químicos e microbiológicos foram baseadas no "STANDARD METHODS FOR THE EXAMINATION OF WATER AND WASTEWATER” da AWWA (2005) $22^{\mathrm{a}}$ ed. Em campo, com o auxílio de uma sonda multiparâmetros Akso COMBO 5, foram registradas as concentrações de condutividade elétrica e $\mathrm{pH}$.

\subsection{PONTOS DE AMOSTRAGEM}

Foram selecionados 8 (oito) pontos para monitoramento limnológico e da qualidade das águas da área de influência do reservatório, ele está localizado no município de Unaí/MG.

Tabela 1: Relação dos pontos de amostragem e respectivas localizações e coordenadas

\begin{tabular}{|c|c|c|c|}
\hline Ponto & Local & Latifude (Sul) & Longitude (Oest) \\
\hline 1 & Montante do reservatório & $16^{\circ} 11^{\prime} 42.97^{\prime \prime}$ & $47^{\circ} 09^{\prime} 20.90^{\prime \prime}$ \\
\hline 2 & Reservatóro - a montante da foz do córrego Jacu & $16^{\circ} 11^{\prime} 3.19^{\prime \prime}$ & $47^{\circ} 06^{\prime} 36.76^{\prime \prime}$ \\
\hline 3 & Jusante da foz do córrego Jacu & $16^{\circ} 10^{\prime} 18.05^{\prime \prime}$ & $47^{\circ} 03^{\prime} 48.96^{\prime \prime}$ \\
\hline 4 & Reservatório & $16^{\circ} 10^{\prime} 31.23^{\prime \prime}$ & $47^{\circ} 02^{\prime} 00.28^{\prime \prime}$ \\
\hline 5 & Ribeirão Santa Maria & $16^{\circ} 11^{\prime} 10.89^{\prime \prime}$ & $47^{\circ} 00^{\prime} 34,35^{\prime \prime}$ \\
\hline 6 & Próximo ao eixo da barragem & $16^{\circ} 11^{\prime} 14.74^{\prime \prime}$ & $47^{\circ} 01^{\prime} 37.77^{\prime \prime}$ \\
\hline 7 & Montante do reservatório & $16^{\circ} 11^{\prime} 36.27^{\prime \prime}$ & $47^{\circ} 10^{\prime} 15.19^{\prime \prime}$ \\
\hline 8 & Montante da área de influência & $16^{\circ} 11^{\prime} 46.41^{\prime \prime}$ & $47^{\circ} 00^{\prime} 15.99^{\prime \prime}$ \\
\hline
\end{tabular}

Fonte: Certificados de ensaio (Laboratório Água e Terra). 
Figura 1: Pontos amostrais para o monitoramento limnológico da área de influência

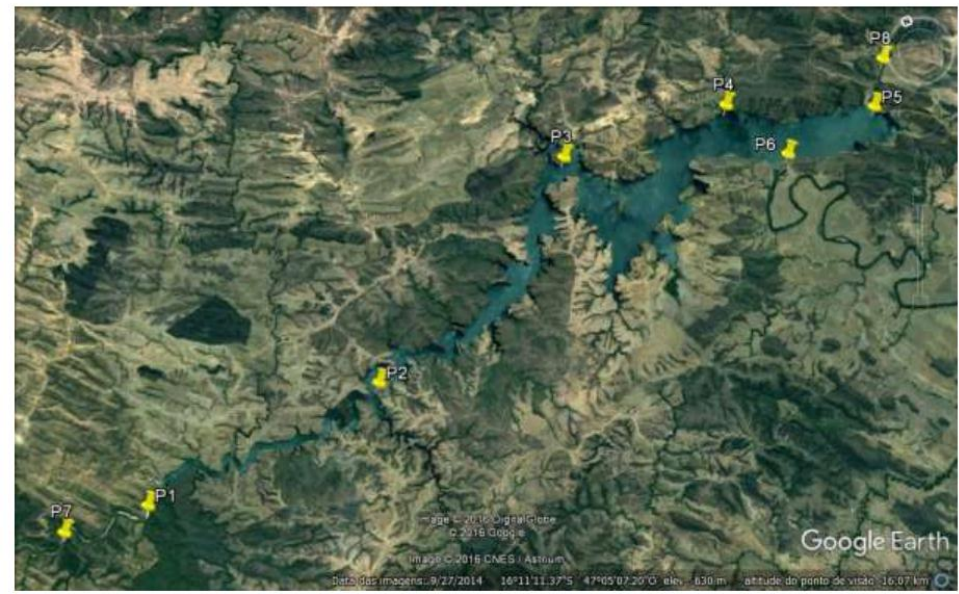

FONTE: Imagens Software Google Earth (data: 27/09/2014).

As campanhas foram realizadas em outubro/2016 e janero/2017, abrangendo os seguintes parâmetros:

Tabela 2: Relação dos parâmetros analisados

\begin{tabular}{c|c}
\hline Parâmetros & Unidades de Medida \\
\hline Temperatura da Amostra & ${ }^{\circ} \mathrm{C}$ \\
Oxigênio Dissolvido & - \\
Demanda Bioquímica Oxigênio & $\mathrm{mg} / \mathrm{L}$ \\
Demanda Química de Oxigênio & $\mathrm{mg} / \mathrm{L}$ \\
Coliformes Termotolerantes & $\mathrm{mg} / \mathrm{L}$ \\
Condutividade Elétrica & $\mathrm{NPM} / 100 \mathrm{~mL}$ \\
Cor Verdadeira & $\mu \mathrm{s} / \mathrm{cm}$ \\
Nitrato & $\mathrm{mgPt} / \mathrm{L}$ \\
Fósforo Totais & $\mathrm{mg} / \mathrm{L}$ \\
\hline
\end{tabular}

4.2. Análises físico-químicas e microbiológicas

A interpretação dos resultados das análises tornou como base a Resolução CONAMA $n^{\circ} 357 / 2005$, que dispõe sobre a classificação dos corpos hídricos e sobre as diretrizes ambientais para seu enquadramento. As águas do reservatório da PCH Unaí Baixo foram classificadas como água doce de classe 2, cujos limites e padrões estão previstos no artigo 15 da Resolução.

As amostras foram coletadas logo abaixo da superfície (aproximadamente $30 \mathrm{~cm}$ ), fixadas quando necessária e acondicionadas em caixas de isopor com gelo. Em seguida, foram encaminhadas ao Laboratório Água e Terra Ltda, localizado no município de Patos de Minas, MG. 
A partir dos resultados das análises físico-químicas e microbiológicas foi calculado o Índice de Qualidade das Águas (IQA), adaptado da National Sanitation Foundation. A FEAMMG incorporou nove parâmetros considerados relevantes para a avaliação da qualidade das águas, tendo como determinante principal a utilização das mesmas para abastecimento púbico. O IQA foi calculado pelo produtório ponderado dos seguintes parâmetros: Temperatura da amostra, pH, Oxigênio dissolvido, Demanda bioquímica de oxigênio, Coliformes termotolerantes, Nitrato, Fósforo total, Resíduos totais e Turbidez. Foi considerado além desses a Demanda Química de Oxigênio (DQO), posto a sua relevância na qualidade de um corpo hídrico. A variação do IQA ocorre de 0 a 100, conforme especificado na tabela a seguir:

Tabela 3: Padrão de IQA

\begin{tabular}{c|c}
\hline Categoria & Ponderação \\
\hline Excelente & $90<$ IQA $<=100$ \\
Bom & $70<$ IQA $<=90$ \\
Médio & $50<$ IQA $<=70$ \\
Regular & $25<$ IQA $<=50$ \\
Muito Ruim & $0<$ IQA $<=25$ \\
\hline
\end{tabular}

4 RESULTADOS E DUSCUSSÃO

Os resultados da análise da água do reservatório da PCH Unaí Baixo obtidos em outubro/2016 e janeiro/2017, e que foram comparados com os limites preconizados pela Resolução CONAMA n³57/2005 para águas doces de classe 2 e são discutidos individualmente no decorrer deste trabalho (Tabelas 3).

Tabela 4: Resultados das variáveis físico-químicas obtidos na área de influência da usina

\begin{tabular}{|c|c|c|c|c|c|c|c|c|c|c|}
\hline \multirow[t]{2}{*}{ Parâmetros } & \multirow{2}{*}{$\begin{array}{c}\text { Unidades de } \\
\text { Medida }\end{array}$} & \multirow[t]{2}{*}{ VMP } & \multicolumn{8}{|c|}{ Outubro/2017 } \\
\hline & & & Ponto 1 & Ponto 2 & Ponto 3 & Ponto 4 & Ponto 5 & Ponto6 & Ponto 7 & Ponto 8 \\
\hline Temperatura da Amostra & ${ }^{\circ} \mathrm{C}$ & N.a. & 27,3 & 28 & 27 & 27 & 31 & 34 & 26,5 & 31 \\
\hline $\mathrm{pH}$ & & 6,0 a 9,0 & 7,31 & 7,89 & 7,15 & 7,44 & 7,18 & 7,55 & 7,63 & 7,31 \\
\hline Oxigênio Dissolvido & $\mathrm{mg} / \mathrm{L}$ & $>5$ & 7,8 & 7,15 & 7,16 & 7,47 & 7,87 & 5,95 & 7,34 & 9,66 \\
\hline Demanda Bioquímica Oxigênio & $\mathrm{mg} / \mathrm{L}$ & $<5$ & $<2,0$ & 2,46 & $<2,0$ & $<2,0$ & $<2,0$ & $<2,0$ & $<2,0$ & $<2,0$ \\
\hline Demanda Química de Oxigênio & $\mathrm{mg} / \mathrm{L}$ & N.a. & $<50,0$ & $<50,0$ & $<50,0$ & $<50,0$ & $<50,0$ & $<50,0$ & $<50,0$ & $<50,0$ \\
\hline Coliformes Termotolerantes & $\mathrm{NPM} / 100 \mathrm{~mL}$ & 1000 & 34 & 27 & 240 & 2 & 4 & 1,8 & 27 & 2 \\
\hline Condutividade Elétrica & $\mu \mathrm{s} / \mathrm{cm}$ & N.a. & 56,3 & 52,4 & 61 & 58,9 & 54,2 & 63,2 & 52,8 & 290 \\
\hline Cor Verdadeira & $\mathrm{mgPt} / \mathrm{L}$ & 75 & $<2,5$ & $<2,5$ & $<2,5$ & $<2,5$ & $<2,5$ & $<2,5$ & $<2,5$ & $<2,5$ \\
\hline Nitrato & $\mathrm{mg} / \mathrm{L}$ & 10 & $<0,1360$ & $<0,1360$ & $<0,1360$ & $<0,1360$ & $<0,1360$ & $<0,1360$ & $<0,1360$ & $<0,1360$ \\
\hline Fósforo Totais & $\mathrm{mg} / \mathrm{L}$ & 0,03 lent; 0,100 lót & 0,01848 & $<0,01000$ & 0,01024 & $<0,01000$ & $<0,01000$ & $<0,01000$ & 0,015 & $<0,01000$ \\
\hline Sólidos Sedimentáveis & $\mathrm{mg} / \mathrm{L}$ & N.a. & $<0,3$ & $<0,3$ & $<0,3$ & $<0,3$ & $<0,3$ & $<0,3$ & $<0,3$ & $<0,3$ \\
\hline Sólidos Suspensos Totais & $\mathrm{mg} / \mathrm{L}$ & 100 & $<10$ & $<10$ & $<10$ & $<10$ & $<10$ & $<10$ & $<10$ & $<10$ \\
\hline Sólidos Totais & $\mathrm{mg} / \mathrm{L}$ & N.a. & 58,667 & 62,667 & 56,667 & 58,667 & 64,667 & 66,667 & 56,667 & 129,67 \\
\hline Turbidez & UNT & 100 & 4,6 & 1,86 & 1,77 & 1,64 & 1,68 & 1,88 & 2,88 & 1,83 \\
\hline
\end{tabular}

Fonte: Certificados de ensaio (Laboratório de Análises Água e Terra). 
Tabela 5: Resultados das variáveis físico-químicas obtidos em janeiro/2017

\begin{tabular}{|c|c|c|c|c|c|c|c|c|c|c|}
\hline \multirow{2}{*}{ Parâmetros } & \multirow{2}{*}{$\begin{array}{l}\text { Unidades de } \\
\text { Medida }\end{array}$} & \multirow{2}{*}{ VMP } & \multicolumn{8}{|c|}{ Janeiro/2016 } \\
\hline & & & Ponto 1 & Ponto 2 & Ponto 3 & Ponto 4 & Ponto 5 & Ponto 6 & \begin{tabular}{|l} 
Ponto 7 \\
\end{tabular} & Ponto 8 \\
\hline Temperatura da Amostra & ${ }^{\circ} \mathrm{C}$ & N.a. & 25,5 & 25,5 & 25 & 28,5 & 31,5 & 34 & 24,6 & 26,1 \\
\hline $\mathrm{pH}$ & & 6,0 a 9,0 & 7,65 & 7,44 & 7,83 & 7,72 & 7,91 & 7,76 & 7,65 & 7,97 \\
\hline Oxigênio Dissolvido & $\mathrm{mg} / \mathrm{L}$ & $>5$ & 3,75 & 6,53 & 8,52 & 9,32 & 9,04 & 4,75 & 4,02 & 9,98 \\
\hline Demanda Bioguímica Oxigênio & $\mathrm{mg} / \mathrm{L}$ & $<5$ & 4,92 & 6,59 & 2,89 & 2,45 & 2,03 & 2,91 & 3,87 & 5,67 \\
\hline Demanda Química de Oxigênio & $\mathrm{mg} / \mathrm{L}$ & N.a. & 89,3 & $<50,0$ & $<50,0$ & $<50,0$ & $<50,0$ & $<50,0$ & 109,3 & 167,7 \\
\hline Coliformes Termotolerantes & $\mathrm{NPM} / 100 \mathrm{~mL}$ & 1000 & 461,1 & 131,4 & 22,6 & 3,1 & 3,1 & 172,5 & 387,5 & 2419,6 \\
\hline Condutividade Elétrica & $\mu \mathrm{s} / \mathrm{cm}$ & N.a. & 155,8 & 98,8 & 114,2 & 98,8 & 108,1 & 113 & 313 & 61,8 \\
\hline Cor Verdadeira & $\mathrm{mgPt} / \mathrm{L}$ & 75 & 10 & 10 & 5 & 10 & 5 & 10 & 10 & 10 \\
\hline Nitrato & $\mathrm{mg} / \mathrm{L}$ & 10 & $<0,1360$ & 0,1472 & $<0,1360$ & $<0,1360$ & $<0,1360$ & $<0,1360$ & $<0,1360$ & $<0,1360$ \\
\hline Fósforo Totais & $\mathrm{mg} / \mathrm{L}$ & 0,03 lent; 0,100 lót & 0,04896 & 0,03356 & $<0,01000$ & 0,01246 & 0,03053 & 0,02324 & 0,11209 & 0,15089 \\
\hline Sólidos Sedimentáveis & $\mathrm{mg} / \mathrm{L}$ & N.a. & 58,667 & 62,667 & 56,667 & 58,667 & 64,667 & 66,667 & 56,667 & 129,67 \\
\hline Sólidos Suspensos Totais & $\mathrm{mg} / \mathrm{L}$ & 100 & 1 3 & 34,3 & $<10$ & 21,1 & $<10$ & 33,7 & 94 & 1671 \\
\hline Sólidos Totais & $\mathrm{mg} / \mathrm{L}$ & N.a. & 159 & 106,7 & 55 & 75,7 & 55 & 87,7 & 165,7 & 178,5 \\
\hline Turbidez & UNT & 100 & 230 & 102 & 9,86 & 26,5 & 23,5 & 79,6 & 234 & $>500$ \\
\hline
\end{tabular}

Obs: Os valores em destaque referem-se aqueles que se apresentaram em desacordo com os limites preconizados na legislação.

Fonte: Certificados de ensaio (Laboratório de Análises Água e Terra).

\subsection{OXIGÊNIO DISSOLVIDO, DBO e DQO}

De acordo com a Resolução CONAMA 357/2005, para que as condições de qualidade dos cursos d'água de Classe 2 sejam mantidas, o limite de OD não deve ser inferior a $5 \mathrm{mg} / \mathrm{L}$, enquanto que o limite máximo para DBO não devem extrapolar o limite de até 5,0 $\mathrm{mg} / \mathrm{L}$.

Como observado na tabela anterior, na campanha de outubro/2016 todos os pontos monitorados apresentaram resultados em conformidade com a legislação para o oxigênio dissolvido, visto que os valores obtidos foram maior que $5,95 \mathrm{mg} / \mathrm{L}$. Já na campanha de janeiro/2017 o VMP foi extrapolado em três pontos. O que indica "teoricamente" aumento de matéria orgânica.

Essa teoria se concretiza observando esse parâmetro (DBO). Na segunda campanha, em todos os pontos foi quantificado o aumento deste, destaque para os pontos $02 \mathrm{e}$ 08, os quais extrapolaram o VMP permitido pela legislação.

Durante as campanhas realizadas, a maioria dos pontos monitorados apresentaram resultados para DQO abaixo do limite de quantificação empregado pelo laboratório, salve em três pontos na segunda campanha, mas nada preocupante.

\section{2 VARIÁVEIS INDICADORAS DE LUMINOSIDADE SUBAQUÁTICA}

A turbidez é a medida da dificuldade de um feixe de luz atravessar certa quantidade de água, conferindo uma aparência turva à mesma. As principais causas da turbidez da água são: presença de matérias sólidas em suspensão (silte, argila, sílica, 
colóides), matérias orgânicas e inorgânicas finamente divididas, organismos microscópicos e algas. A origem desses materiais pode ser o solo, a mineração, as indústrias ou o esgoto doméstico lançado no manancial sem tratamento.

Outro parâmetro indicador de luminosidade aquática é a cor, que está associada ao grau de redução de intensidade que a luz sofre ao atravessá-la (e esta redução dá-se por absorção de parte da radiação eletromagnética).

Os dois parâmetros apresentados nas tabela 3, apresentaram valores em conformidade com a Resolução CONAMA 357/2005.

Já em janeiro/2017 os valores obtidos estiveram aumentados para ambos os parâmetros, sendo que para a cor verdadeira os resultados oscilaram de $5 \mathrm{mgPt} / \mathrm{L}$ a 40 mgPt/L. Para turbidez registrou-se valores superiores ao limite permitido pela legislação (>100 NTU) nos pontos 01, 02, 07 e 08 .

\subsection{SÓLIDOS SEDIMENTAVES, SUSPENSOS E TOTAIS}

Para os sólidos sedimentáveis e sólidos totais não há limite pré-estabelecido na legislação. Já sólidos suspensos totais a Resolução CONAMA 357/2005 estabelece um limite máximo de $100 \mathrm{mg} / \mathrm{L}$ para os cursos d'água de Classe 2.

Conforme amostrado, os sólidos sedimentáveis não foram detectados em nenhum dos pontos monitorados nas duas campanhas, visto que os valores apresentados foram inferiores ao limite de detecção.

Os valores obtidos para os sólidos suspensos totais foram menores que o limite de quantificação, enquanto que para os sólidos totais as concentrações oscilaram de $56,667 \mathrm{mg} / \mathrm{L}$ nos pontos 03 e 07 a 129,67 mg/L no ponto 08. Os sólidos suspensos totais não foram detectados apenas nos pontos 03 e 05 , enquanto que nos demais os resultados amostrados variaram de $21,1 \mathrm{mg} / \mathrm{L}$ a $1671 \mathrm{mg} / \mathrm{L}$, sendo que nos pontos 01 e 08 os valores obtidos foram superiores ao limite máximo permitido, fato que pode estar relacionado com as chuvas que precederam as coletas. Já para os sólidos totais os valores registrados oscilaram de $55 \mathrm{mg} / \mathrm{L}$ nos pontos 03 e 05 a $1785 \mathrm{mg} / \mathrm{L}$ no ponto 08 .

\subsection{PH E CONDUTIVIDADE ELETRICA}

A Resolução CONAMA 357/2005 não estabelece limite para a condutividade elétrica, enquanto que para o $\mathrm{pH}$ os valores devem estar entre 6,0 e 9,0. 
A condutividade elétrica apresentou elevado valor no ponto 08 , correspondendo a $290 \mu \mathrm{S} / \mathrm{cm}$, enquanto que para os demais pontos avaliados os resultados amostrados apresentaram média de 56,97 $\mu \mathrm{S} / \mathrm{cm}$. Já na campanha de janeiro/2017 os valores obtidos para esse parâmetro oscilaram de $61,8 \mu \mathrm{S} / \mathrm{cm}$ no ponto 08 a $313 \mu \mathrm{S} / \mathrm{cm}$ no ponto 07 .

Durante as campanhas realizadas os valores obtidos para o $\mathrm{pH}$ se mantiveram similares em todos os pontos analisados.

\subsection{FÓSFORO TOTAL}

$\mathrm{Na}$ maioria das águas continentais, o fósforo é o principal fator limitante de sua produtividade. Além disso, tem sido apontado como um dos principais responsáveis pela eutrofização artificial destes ecossistemas. Toda forma de fósforo presente em águas naturais, quer na forma iônica quer na forma complexada, encontra-se sob a forma de fosfato.

Para as águas doces de Classe 2, a Resolução CONAMA 357/2005 estabelece, para as águas superficiais, os seguintes limites para fósforo total:

- Até $0,030 \mathrm{mg} / \mathrm{L}$ em ambientes lênticos;

- Até 0,050 mg/L, em ambientes intermediários, com tempo de residência entre 2 e 40 dias, e tributários diretos de ambiente lêntico;

- Até $0,100 \mathrm{mg} / \mathrm{L}$, para ambientes lóticos e tributários de ambientes intermediários.

Como observado o fósforo total apresentou concentrações mais elevadas em janeiro/2017, possivelmente influenciadas pela entrada de material alóctone advinda das chuvas que antecederam as coletas.

Em outubro/2016 esse parâmetro foi detectado somente nos pontos 01, 03 e 07, estando todos em conformidade com o estabelecido na legislação.

Já na campanha de janeiro/2017 foi registrada concentração de fósforo total inferior ao limite de quantificação $(<0,010 \mathrm{mg} / \mathrm{L})$ somente no ponto 03 , enquanto que nos demais os valores obtidos oscilaram de $0,01246 \mathrm{mg} / \mathrm{L}$ no ponto 04 a $0,15089 \mathrm{mg} / \mathrm{L}$ no ponto 08. Nessa campanha foram registrados resultados superiores ao limite permitido para ambientes lóticos nos pontos 07 e 08 . Como não há registros de lançamento de efluentes sanitários e industriais no reservatório da $\mathrm{PCH}$ Unaí Baixo ou em seus contribuintes, a principal fonte desse parâmetro é o carreamento de materiais alóctones para dentro do corpo hídrico causado pelas chuvas. 


\subsection{NITRATO}

Como observado na tabela 3 (outubro/2016) o parâmetro nitrato apresentou concentrações menores que o limite de quantificação do laboratório em todos os pontos monitorados.

Em janeiro/2017 o nitrato apresentou valor superior ao limite de detecção apenas no ponto $02(0,1472 \mathrm{mg} / \mathrm{L})$.

De acordo com os resultados apresentados, verificou-se que este parâmetro apresenta concentrações dentro dos limites estabelecidos pela Resolução CONAMA 357/2005 tanto em outubro/2016 quanto em janeiro/2017.

\subsection{COLIFORMES TERMOTOLERANTES}

Pertencem ao grupo dos coliformes os gêneros bacterianos Escherichia, Enterobacter, Klebsiella e Citrobacter, incluindo cerca de 20 espécies, dentre as quais encontram-se tanto bactérias originárias do trato gastrintestinal de humanos e outros animais de sangue quente, como também diversos gêneros e espécies de bactérias não entéricas. Por isso sua enumeração em água e alimentos é menos representativa, como indicação de contaminação fecal, do que a enumeração de coliformes fecais ou E. coli (SILVA et al., 2005).

A legislação vigente estabelece que para águas doces de Classe 2, o parâmetro coliformes termotolerantes não deverá exceder o limite de 1.000 coliformes termotolerantes por 100 mililitros em $80 \%$ ou mais de pelo menos seis amostras coletadas durante o período de um ano. Para os demais parâmetros microbiológicos, a legislação não estabelece limites.

Os coliformes termotolerantes foram detectados em todos os pontos monitorados em ambas as campanhas, sendo que apenas o ponto 08 em janeiro/2017 apresentou resultado em desacordo com o limite estabelecido pela legislação, sendo registrado nesse ponto valor correspondendo a >2419,6 NMP/100 mL.

As chuvas que ocorreram antes das coletas realizadas em janeiro/2017 podem ter contribuído para o aumento nas concentrações dos parâmetros, visto que o escoamento de partículas do solo para dentro dos cursos d'água é intensificado, promovendo o incremento de várias substâncias nas águas que compõe o empreendimento. 


\section{9 ÍNDICE DE QUALIDADE DAS ÁGUAS (IQA)}

O IQA é uma ferramenta importante por fornecer um diagnóstico geral sobre o estado do corpo d'água e facilitar a tomada de decisão para atuar preventiva ou corretivamente sobre o recurso hídrico. Além disso, representa uma média de diversas variáveis em um único número, combinando unidades de medidas diferentes em uma única unidade. No entanto, a avaliação dos valores de parâmetros individuais não deve ser desprezada, pois o índice pode escamotear problemas relacionados a determinados parâmetros.

Os resultados obtidos se encontram na tabela a baixo:

\begin{tabular}{|c|c|c|c|c|}
\multicolumn{5}{c}{ Tabela 6 - Resultados do IQA } \\
\hline \multirow{2}{*}{ Ponto de Amostragem } & \multicolumn{3}{|c}{ Outubro/2017 } & \multicolumn{2}{c}{ Janeiro/2017 } \\
\cline { 2 - 5 } IQA & Qualidade & IQA & Qualidade \\
Ponto 01 & 85,11 & Bom & 49,58 & Ruim \\
Ponto 02 & 84,64 & Bom & 59,36 & Médio \\
Ponto 03 & 78,71 & Bom & 84,1 & Bom \\
Ponto 04 & 92,46 & Excelente & 86,02 & Bom \\
Ponto 05 & 90,78 & Excelente & 85,82 & Bom \\
Ponto 06 & 91,73 & Excelente & 67,77 & Médio \\
Ponto 07 & 85,27 & Bom & 50,83 & Médio \\
Ponto 08 & 89,76 & Bom & 47,44 & Ruim \\
\hline
\end{tabular}

Fonte: Relatório de monitoramento (Laboratório de Análises Água e Terra).

\section{CONCLUSÕES}

Com base nos resultados apresentados anteriormente, pode-se afirmar que todos os parâmetros físico-químicos e microbiológicos analisados na área de influência da PCH Unaí Baixo, apresentaram-se em acordo com os limites estabelecidos na Resolução CONAMA 357/2005, para as águas doces de Classe 2.

Os pontos monitorados, assim como em campanhas anteriores, apresentaram águas bem oxigenadas e valores de $\mathrm{pH}$ tendendo a alcalinidade. As concentrações dos compostos de fósforo e nitrogênio registradas na $\mathrm{PCH}$ foram baixas, sendo que na maioria das amostras os valores obtidos não ultrapassam os limites de quantificação estabelecido pelo laboratório. Para o IQA os pontos amostrados apresentaram águas classificadas como de boa e excelente qualidade. 
As maiores variações foram registradas no ponto 08 (Ribeirão Santa Maria), fato já verificado em monitoramentos realizados anteriormente e que pode estar relacionado com as características próprias do curso d'água. Os principais parâmetros que evidenciaram essas alterações foram sólidos totais, condutividade elétrica, alcalinidade e dureza.

A qualidade da água na área de influência da PCH Unaí Baixo foi considerada boa. Assim, é importante ressaltar a necessidade da continuidade do monitoramento dos parâmetros físico-químicos e microbiológicos, com o objetivo de examinar alterações da qualidade da água e propor medidas quando necessário.

\section{BIBLIOGRAFIA}

AGUA E TERRA. Monitoramento Liminológico e de Qualidade das Águas da PCH Baixo, 2017.

APHA. Standard Methods for the examination of water \& wastewater. 21 ed. 2005.

CAVENGHI, A.L., et al., Caracterização da qualidade de água e sedimento relacionados com a ocorrência de plantas aquáticas em cinco reservatórios da bacia do rio Tietê. Planta Daninha, Viçosa-MG. v.21, p.43-52, 2003.

CONAMA - Conselho Nacional de Meio Ambiente. Resolução CONAMA 357/2005, de 17 de março de 2005.

FEAM - Fundação Estadual do Meio Ambiente. Manual de Saneamento e Proteção Ambiental para os municípios. V.5. 3 ed. Belo Horizonte: FEAM, 2002.

GOULART, M. \& CALLISTO, M. 2003.Bioindicadores de qualidade de água como ferramenta em estudos de impacto ambiental. Revista da FAPAM, ano 2, no 1. IGAM Instituto Mineiro de Gestão das Águas. 2007.

PEDREIRA, A.C. Avaliação do processo de licenciamento ambiental para pequenas centrais hidrelétricas no Estado de Minas Gerais. Dissertação apresentada ao Programa de Pósgraduação em Engenharia da Energia. Universidade Federal de Itajubá. Itajubá, MG. 2004.

SILVA, Neusely; et al. Manual de métodos de análise microbiológica da água. São Paulo: Livraria Varela Editora, 2005.

SOUZA, M. A. A. de. Meio ambiente e desenvolvimento sustentável: as metáforas do capitalismo. 2007. Disponível em: <http://www.territorial.org.br/material/meioambiente.pdf>; <http://docentes.puc-campinas.edu.br/ceatec/lucasm/ textos/meioambiente.pdf >. 